\title{
CXCR4 inhibitors selectively eliminate CXCR4-expressing human acute myeloid leukemia cells in NOG mouse model
}

\author{
Y Zhang ${ }^{1,2,3}$, S Patel ${ }^{1,2,3}$, H Abdelouahab ${ }^{1,3,4}$, M Wittner ${ }^{1,2,3}$, C Willekens ${ }^{1,2,3}$, S Shen ${ }^{2,3,5}$, A Betems ${ }^{1,2,3}$, V Joulin ${ }^{1,2,3}$, P Opolon ${ }^{3,6}$, \\ O Bawa ${ }^{3,6}$, F Pasquier ${ }^{2,3}$, M Ito ${ }^{7}$, N Fujii' ${ }^{8}$, P Gonin ${ }^{9}$, E Solary ${ }^{1,2,3}$, W Vainchenker ${ }^{1,2,3}$, P Coppo ${ }^{1,10,11}$, S De Botton ${ }^{2,3,12,13}$ \\ and $F$ Louache ${ }^{\star, 1,2,3}$
}

The chemokine receptor CXCR4 favors the interaction of acute myeloid leukemia (AML) cells with their niche but the extent to which it participates in pathogenesis is unclear. Here, we show that CXCR4 expression at the surface of leukemic cells allowed distinguishing CXCR4 ${ }^{\text {high }}$ from CXCR4 ${ }^{\text {neg/low }}$ AML patients. When high levels of CXCR4 are expressed at the surface of AML cells, blocking the receptor function with small molecule inhibitors could promote leukemic cell death and reduce NOD/Shi-scid/IL$2 \mathrm{R} \gamma^{\text {null }}$ (NOG) leukemia-initiating cells (LICs). Conversely, these drugs had no efficacy when AML cells do not express CXCR4 or when they do not respond to chemokine CXC motif ligand 12 (CXCL12). Functional analysis showed a greater mobilization of leukemic cells and LICs in response to drugs, suggesting that they target the interaction between leukemic cells and their supportive bone marrow microenvironment. In addition, increased apoptosis of leukemic cells in vitro and in vivo was observed. CXCR4 expression level on AML blast cells and their migratory response to CXCL12 are therefore predictive of the response to the inhibitors and could be used as biomarkers to select patients that could potentially benefit from the drugs.

Cell Death and Disease (2012) 3, e396; doi:10.1038/cddis.2012.137; published online 4 October 2012

Subject Category: Experimental Medicine

Chemokine CXC motif ligand 12 (CXCL12), also known as SDF-1, is a homeostatic chemokine constitutively produced by bone marrow (BM) stromal cells. ${ }^{1}$ CXCL12 binds to CXCR4, a member of a large family of seven-transmembrane domain receptors coupled to heterotrimeric $G_{i}$ proteins. CXCR4 is a cell surface receptor expressed on many cell types, including hematopoietic stem and progenitor cells (HSPC). ${ }^{2,3}$ Mice with either CXCL12 or CXCR4 gene disruption display deficient HSPC colonization of their $\mathrm{BM}^{4-6}$ and transplantation experiments demonstrated that CXCR4 is required for long-term lymphoid and myeloid reconstitution. ${ }^{7}$ CXCL12 stimulates integrin activity, favoring HSPC interaction with their microenvironment. ${ }^{8,9}$ Hence, CXCL12/CXCR4 signaling has a critical role in the retention of HSPC in BM niches. ${ }^{10,11}$ Besides this pro-adhesive activity, CXCL12/ CXCR4 may directly regulate HSPC proliferation, survival and differentiation. ${ }^{12,13}$ Recently, several small molecule competitive antagonists of CXCR4 have been described, of which AMD3100 has been administrated to human subjects.
These inhibitors antagonize CXCL12 binding to CXCR4, disrupt CXCL12-mediated chemotaxis and induce mobilization of HSPC into peripheral blood. ${ }^{14-17}$

Acute myeloid leukemia $(A M L)$ represents a heterogeneous group of hematopoietic malignancies with various morphological features, genomic abnormalities and clinical manifestations. Despite this heterogeneity, many primary AML retain a number of characteristics of normal hematopoiesis including a cell hierarchy organization. ${ }^{18,19}$ This includes the presence of a small subset of AML cells, referred to as SCID-LICs (leukemia-initiating cells) or leukemic stem cells, at the top of this hierarchy, which perpetuates the disease. ${ }^{18,20-22}$ Although characterized by uncontrolled growth and survival advantage, most primary AML cells retain dependency on BM microenvironment or niches, which might be their Achilles' heel. $^{23}$ However, leukemic cells are often found in extramedullary sites, suggesting that permissive niches may also exist in other sites. ${ }^{24,25}$ Similarly to its role in normal hematopoiesis, the CXCR4/CXCL12 axis also acts as a

\footnotetext{
${ }^{1}$ Institut National de la Santé et de la Recherche Médicale (INSERM), U1009, 114 rue Edouard Vaillant, 94805 Villejuif, France; ${ }^{2}$ Université Paris Sud, 114 rue Edouard Vaillant, 94805 Villejuif, France; ${ }^{3}$ Institut Gustave Roussy, IFR54, 114 rue Edouard Vaillant, 94805 Villejuif, France; ${ }^{4}$ Université Paris VII, 5 Rue Thomas Mann, 75013 Paris, France; ${ }^{5}$ INSERM, U848, 114 rue Edouard Vaillant, 94805 Villejuif, France; ${ }^{6}$ Institut Gustave Roussy, IRCIV, Laboratoire de Pathologie Experimentale, 114 Edouard Vaillant, 94805 Villejuif, France; ${ }^{7}$ Laboratory Animal Research Department, Central Institute for Experimental Animals, Kawasaki, Japan; ${ }^{8}$ Kyoto University, Graduate School of Pharmaceutical Sciences, Kyoto, Japan; ${ }^{9}$ Institut Gustave Roussy, IRCIV, Plateforme d'Evaluation Préclinique, 114 Edouard Vaillant, 94805 Villejuif, France; ${ }^{10}$ Département d'Hématologie, 184 Rue du Faubourg Saint-Antoine, 75012 Paris, France; ${ }^{11}$ Université Paris VI, 4 Place Jussieu, 75005 Paris, France; ${ }^{12}$ Département d'Hématologie, Institut Gustave Roussy, 114 rue Edouard Vaillant, 94805 Villejuif, France and ${ }^{13}$ Institut National de la Santé et de la Recherche Médicale (INSERM), U985, 114 rue Edouard Vaillant, 94805 Villejuif, France

${ }^{*}$ Corresponding author: F Louache, Institut Gustave Roussy, IFR54, 114 rue Edouard Vaillant, 94805 Villejuif, France. Tel: +33142114233 ; Fax: + 33142115240 ; E-mail: fawl@igr.fr

Keywords: CXCR4; CXCL12; acute myeloid leukemia; niche; leukemia-initiating cells; inhibitors

Abbreviations: AML, acute myeloid leukemia; BM, bone marrow; CFSE, carboxyfluorescein diacetate $\mathrm{N}$-succinimidyl ester; CXCL12, chemokine CXC motif ligand 12; HSPC, hematopoietic stem and progenitor cells; LIC, leukemia-initiating cell; MFIR, Mean fluorescence intensity ratio; NOG, NOD/Shi-scid/L-2R $\gamma^{\text {null }}$

Received 25.6.12; revised 16.8.12; accepted 21.8.12; Edited by G Ciliberto
} 
critical regulator of $\mathrm{AML}$ biology ${ }^{26}$ and high CXCR4 membrane expression on leukemic blasts correlates with a poor prognosis. $^{27,28}$

Accordingly, a therapeutic effect of CXCR4 antagonist Plerixafor (AMD3100) is observed when used in combination with chemotherapy or FLT3 inhibitors in mice bearing human and murine $A M L$ cell lines or in murine genetic model of acute pro-myelocytic leukemia. ${ }^{29,30}$ Moreover, the addition of Plerixafor to cytotoxic chemotherapy in a phase 1/2 study resulted in encouraging rates of remission. ${ }^{31}$ However, the biological effects of these antagonists on primary human AML cells when used alone in vivo remain to be investigated.

Here, we identified two groups of AML patients according to their CXCR4 membrane expression and CXCL12-mediated chemotaxis and report for the first time that the use of CXCR4 antagonists, AMD3100 and TN140 alone selectively induced leukemia regression when AML cells originally expressed high CXCR4 levels and displayed significant migratory response to CXCL12. Thus, this work represents a proof of concept that CXCR4 inhibition, as a single agent, may be a therapeutic approach in selected patients.

\section{Results}

CXCR4 expression and response to CXCL12 are intrinsic features of AML cells. We evaluated the level of CXCR4 membrane expression on leukemic blasts of $47 \mathrm{AML}$ samples that encompassed a broad range of disease subtypes and treatment outcomes. Of 47 samples evaluated, 22 displayed mean fluorescence intensity ratios (MFIRs) below 5 (CXCR4 ${ }^{\text {neg/low }}$ ), whereas 25 displayed MFIRs higher than $5\left(\mathrm{CXCR} 4^{\text {high }}\right)$. For three patients, CXCR4 expression was evaluated on both peripheral and BM samples and no difference in expression was observed (data not shown). The chemotactic response to CXCL12 was analyzed on 41 out of 47 AML samples. The median percentage of cells that had migrated in the presence of CXCL12 was $15 \%$, which exceeded the comparative $2.6 \%$ value in medium alone $(P<0.01)$. Correlation analysis revealed a statistically significant correlation between chemotaxis and the overall CXCR4 expression (Supplementary Figure 1, $r=0.6$, $P=0.00004$ ). To test the in vivo sensitivity of AML primary cells to CXCR4 inhibitors, we choose five AML samples displaying MFIRs below 5 (CXCR4 $\left.4^{\text {neg/low }}\right)$ and three with MFIRs higher than 5 (CXCR4 ${ }^{\text {high }}$ ). The disease details of the selected patients are shown in Table 1. The AML cells that developed in mice exhibited all phenotypic features reminiscent of original patient cells (Supplementary Figure 2). For each specimen, CXCR4 membrane expression was similar before and after engraftment (Figure 1a). CXCL12-induced migration of the eight individual AML samples was also evaluated before and after engraftment. Before transplantation, spontaneous migration (medium alone) of patient cells ranged between 1.3 and $5 \%$, whereas in response to CXCL12 (specific migration) values ranged from 3 to $30 \%$. Among them, four had CXCL12-induced migration close to spontaneous migration indicating weak or even no CXCL12 responsiveness, whereas the four others had significant response to CXCL12 (Figure 1b). After transplantation,
Table 1 Characteristics of AML patient samples

\begin{tabular}{lcccccc}
\hline $\begin{array}{l}\text { Patients } \\
\text { (No.) }\end{array}$ & Sex & Age & $\begin{array}{c}\text { PIS } \\
\text { AML }\end{array}$ & FAB & Karyotype & $\begin{array}{c}\text { WBC } \\
(\times \mathbf{1 0} / \mathbf{l})\end{array}$ \\
\hline 7 & M & 3 & P & 0 & $-5 q$ & 244 \\
12 & M & 67 & P & 0 & $t(9,22)$ & 11.4 \\
13 & M & 48 & P & 2 & Normal & 36 \\
14 & F & 48 & S & 2 & $-5 q,-7$ & 6.7 \\
15 & M & 81 & S & 5 & Normal & 68 \\
16 & F & 77 & P & 1 & Normal & 511 \\
17 & F & 32 & S & 5 & -7, Inv3, & 25.5 \\
18 & F & 39 & P & $5 a$ & $+11 p 13$ & $+8,+13$ \\
\hline
\end{tabular}
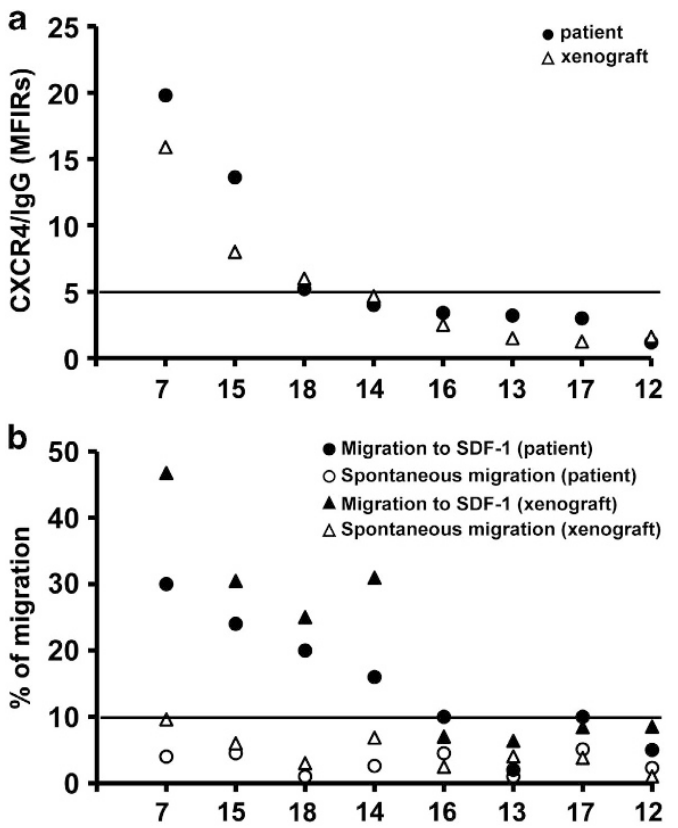

Figure 1 Comparison of CXCR4 expression levels and chemotaxis responses to CXCL12 before and after engraftment. (a) CXCR4 membrane expression levels on AML blasts from patients (black dot) and human leukemic cells isolated from the BM of NOG mice (white triangle) 16 weeks post engraftment. The horizontal line $(\mathrm{MFIRs}=5$ ) indicates the threshold used for stratification. (b) Spontaneous (white dot and white triangle) and specific migration to $100 \mathrm{ng} / \mathrm{ml} \mathrm{CXCL12} \mathrm{(black} \mathrm{dot} \mathrm{and}$ black triangle) of AML blasts from patients (black and white dot) and human leukemic cells isolated from the BM of NOG mice (black and white triangle) 16 weeks post engraftment. The horizontal line shows the highest spontaneous migration ratio $(9.6 \%)$

spontaneous migration of human cells isolated from the mouse BM ranged between 2.5 and $9.6 \%$, whereas specific migration values ranged from 6.4 to $46.8 \%$. Concordant results were obtained between BM and spleen-derived cells for the two patients analyzed (not depicted). For each specimen, CXCL12 response was not significantly different before and after transplantation and non-responders remained non-responders after engraftment (Figure 1b). Therefore, CXCR4 membrane expression and CXCL12 responsiveness represent an intrinsic feature of individual leukemia that is not modified by engraftment and by the NOD/Shi-scid/IL-2R $\gamma^{\text {null }}$ (NOG) mouse microenvironment. 
CXCR4 inhibitors induce regression of CXCR4-expressing AMLs and targeted LICs in the BM. The effects of CXCR4 inhibitors in vivo were determined on leukemic mice generated from these eight samples. Taking into consideration the short in vivo half-life of AMD3100 (3-5h) ${ }^{32}$ and TN140 (9.6 h), ${ }^{33}$ the drugs were administered by s.c. pumps implantation during 7 days. Administration of TN140 or AMD3100 to a lesser extent resulted in a marked decrease in anti-CXCR4 antibody 12G5 binding to AML cells isolated from blood, BM and spleen from mice engrafted with CXCR4 ${ }^{\text {high }}$ cells, while binding was minimally changed in mice engrafted with $\mathrm{CXCR} 4^{\text {neg/low }}$ cells (Figure 2a). This indicates that TN140 or AMD3100 functionally blocks CXCR4 as the 12G5 antibody identifies the epitope involved in $\mathrm{CXCL} 12$ binding. The in vitro migration response to CXCL12 of AML cells isolated from the mouse BM was sharply inhibited by TN140. A much more moderate effect was observed with AMD3100 (Figure 2b), indicating differential efficacy between these two inhibitors.

BM cells were counted and the percentage of human $\mathrm{CD}_{4}{ }^{+} \mathrm{CD} 3^{+}$cells was determined upon 7 day treatment. In four cases (\#7 with AMD3100 and TN40; \#15, \#18 and \#14 with TN140), corresponding to those with higher CXCR4 expression and higher CXCL12 chemotaxis, the total number of leukemic cells was significantly reduced in the BM of treated mice compared with control mice (Figure 3a). For patients 7 and 18, mice treated with TN140 for 7 days demonstrated prolonged overall survival compared with control mice (Figure 3b). AMD3100 administration only moderately increased the survival of treated mice. For patients 7 and 12 , corresponding to those with lower CXCR4 expression and lower CXCL12 chemotaxis, only a small relative effect of CXCR4 inhibitors was observed.

To test if the CXCR4 inhibitors targeted the LICs, CD45 ${ }^{+}$ cells were sorted from the BM of PBS-, AMD3100- or TN140treated mice engrafted with AML cells (\#7 and \#18) and transplanted into secondary hosts. Eight weeks after secondary transplantation, the presence of human myeloid cells $\left(\mathrm{CD} 45^{+} \mathrm{CD}_{3}{ }^{+} \mathrm{CD} 19^{-}\right)$was assessed in the blood. Figure $3 c$ represents the percentage of human cells observed in secondary recipients reconstituted with the BM cells of treated or untreated mice (obtained in Figure 3a) and indicated that the percentage of circulating human cells was much lower in mice transplanted with cells sorted from TN140or AMD3100-treated mice than in control mice. In addition, overall survival of the secondary recipients demonstrated higher survival compared with controls, indicating that LICs were targeted by TN140 and AMD3100 to a lesser extent (Figure 3d).

CXCR4 inhibitors induce regression of CXCR4-expressing AMLs in the mouse tissues. Immunohistological analyses of xenografted mice revealed the presence of large clusters of AML CD45 ${ }^{+}$cells surrounding the bile ducts and along the larger venous in the CXCR $4^{\text {high }}$ group, in addition to isolated cells in sinusoids scattered throughout the parenchyma. In the CXCR $4^{\text {neg/low }}$ group, AML cells appeared to be distributed more homogeneously throughout the parenchyma with small clusters along the large venous (Figure 4a). To understand whether the organ infiltration was

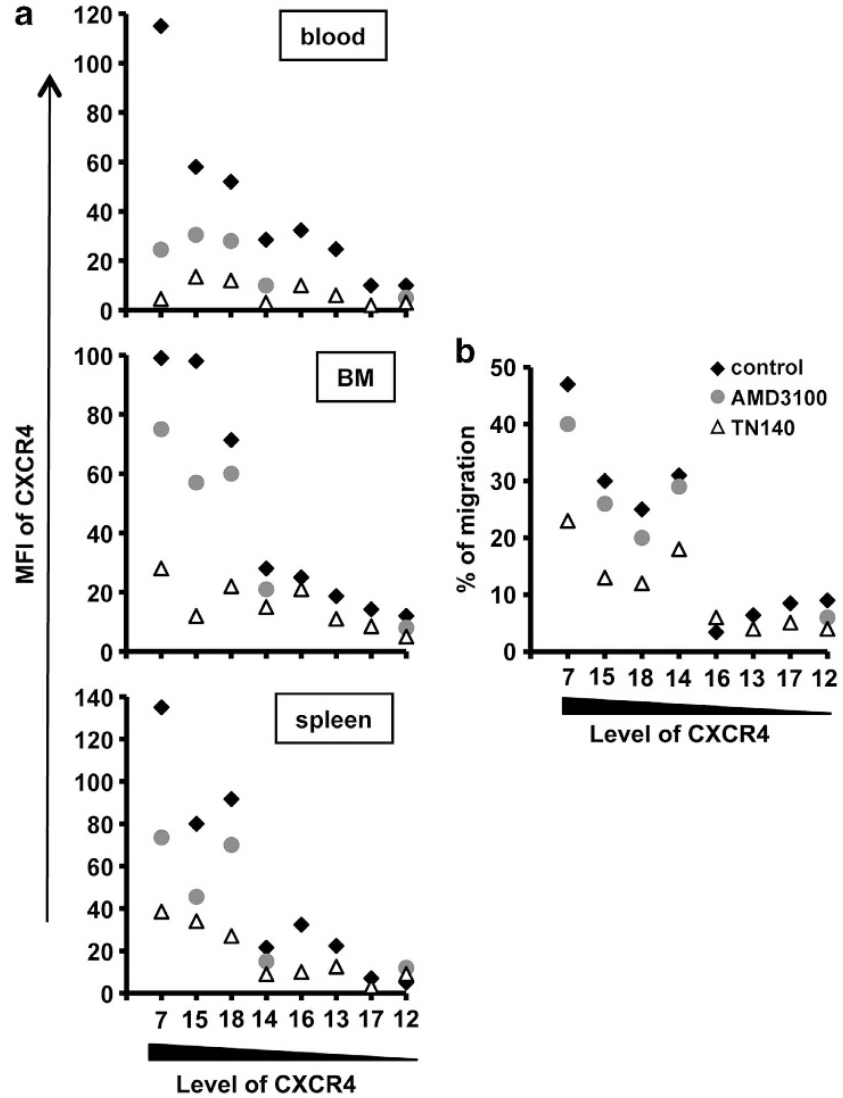

Figure 2 In vivo administration of CXCR4 inhibitors reduces CXCR4 membrane expression and migratory capacity of leukemic cells. NOG mice were engrafted with AML cells from patients indicated below horizontal axis. Twelve to sixteen weeks post transplant, PBS (black diamond), AMD3100 (gray circle) or TN140 (white triangle) was administered s.c. using Alzet osmotic pumps during 7 days. (a) Membrane CXCR4 expression levels on human leukemic cells in blood, BM and spleens by flow cytometry. Each point is the average MFI of CXCR4 for human cells recovered from 4 to 6 mice engrafted with cells from the same patient. (b) Transwell migration of human cells recovered from BM of PBS- and inhibitor-treated mice in response to $100 \mathrm{ng} / \mathrm{ml} \mathrm{CXCL12.} \mathrm{Each} \mathrm{point} \mathrm{is} \mathrm{the} \mathrm{average} \mathrm{migration} \mathrm{ratio} \mathrm{from} \mathrm{four}$ mice

related to CXCL12, we tested CXCL12 mRNA expression in the hematopoietic organs of normal NOG mice. CXCL12 mRNA expression was detected in BM and spleen cells, whereas it was undetectable in blood cells (Figure 4b). CXCL12 protein was detected at a high level in BM supernatant and plasma, and at a lower extent in spleen and liver supernatants (Figure 4c). In liver, CXCL12 was concentrated in the bile duct epithelial cells, as detected by the immunohistochemistry (Figure 4d). These findings indicate that expression of CXCR4 may permit redistribution of AML cells toward CXCL12 synthesizing cells in the liver, suggesting that the dissemination of cells expressing CXCR4 is not random, but might be guided by CXCL12 production in specific sites.

In spleen, leukemic cell number was reduced by AMD3100 and TN140 (\#7 and \#14) or TN140 only (\#15 and \#18) (Figure 4e). In liver, TN140 and AMD3100 more modestly decreased the number of human $\mathrm{CD} 45^{+}$cells infiltrating the sinus or located along the big venous and bile ducts (Figures 


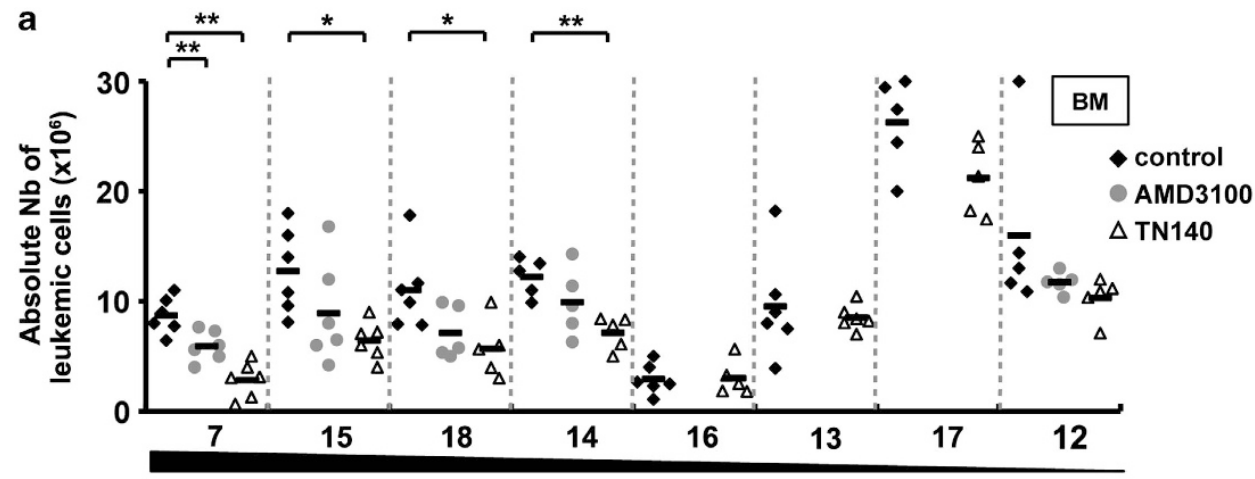

Level of CXCR4

b
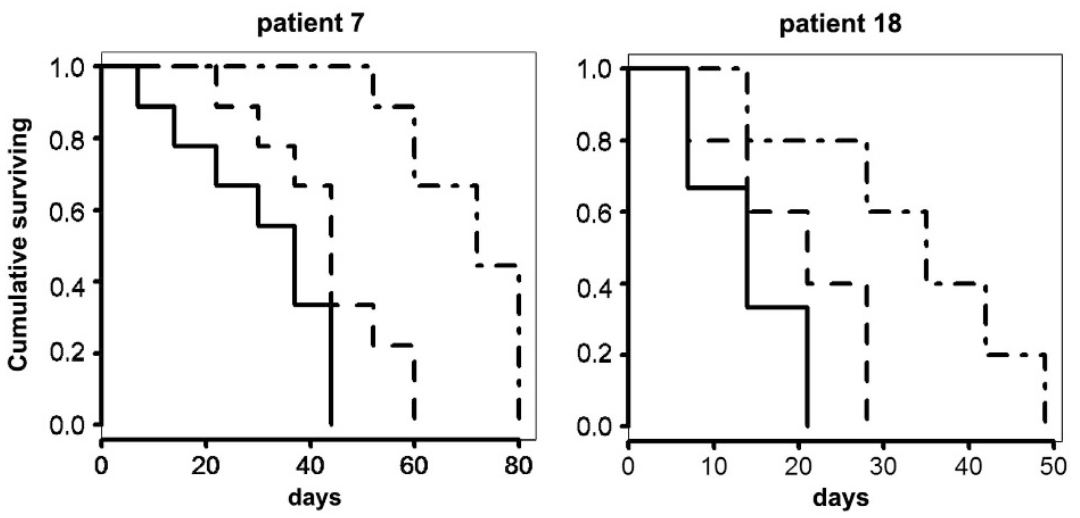

C
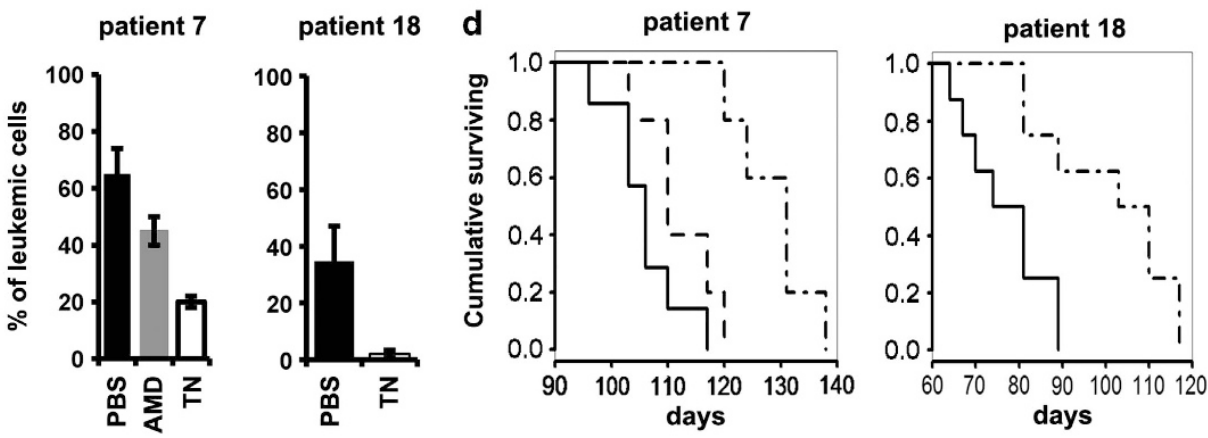

Figure 3 CXCR4 inhibitors induce regression of CXCR4-expressing AMLs and targeted LICs in the BM. (a) PBS (black diamond), AMD3100 (gray circle) or TN140 (white triangle) was administered subcutaneously to xenografted mice using Alzet osmotic pumps during 7 days. BM cells were counted and the percentage of human $\mathrm{CD} 45^{+} \mathrm{CD} 33^{+}$cells was determined by flow cytometry. Each point represents an individual mouse. Horizontal black bars indicate the average level of human cell numbers. Patient numbers are indicated below the graph with an arrow showing decreasing levels of CXCR4 expression by individual specimen. (b) CXCR4 inhibitor treatment prolongs survival of leukemic mice. Inhibitors treatment was stopped at day 8 and mice were kept alive. Survival curve of mice engrafted with cells from patients 7 and 18 . PBS- (black line), AMD3100- (dashed line) and TN140- (dashed dot line) treated mice. Patient 7: Statistical difference: $P=0.05$, between PBS- $(n=9)$ and AMD-treated mice $(n=9)$; $P=0.00003$, between PBS- and TN140-treated mice $(n=9)$. Patient 18: Statistical difference: $P=0.173$, between PBS- $(n=6)$ and AMD-treated mice $(n=5) ; P=0.0125$, between PBS- and TN140-treated mice $(n=6)$ (log-rank test). (c) One hundred microliters of BM cell suspension from PBS- (black bars), AMD3100- (gray bar) and TN140(white bar) treated mice reconstituted with cells of patients 7 and 18 was i.v. injected to secondary mice. Eight weeks later, the percentage of human $\mathrm{CD} 45^{+}$cells in the blood of reconstituted mice histogram was analyzed by cytometry. Data are mean \pm S.D. $\left(n=4\right.$ mice). ${ }^{*} P<0.05,{ }^{* *} P<0.01$ assessed by test of Mann-Whitney. Black histograms represent the percentage of leukemic cells PBS-treated mice. (d) CXCR4 inhibitor treatment prolongs survival of secondary mice. Survival curve of recipients of BM from PBStreated mice (black line), AMD3100-treated mice (dashed line) and TN140-treated mice (dashed dot). Patient 7: Statistical difference: $P=0.12$, between PBS- $(n=7)$ and AMD-treated mice $(n=5) ; P=0.001$, between PBS- and TN140-treated mice $(n=5)$. Patient 18: Statistical difference: $P=0.004$, between PBS- $(n=8)$ and TN140-treated mice $(n=8)$ (log-rank test)

$4 f-h)$. Thus, CXCR4 inhibitors induced leukemic regression in the BM, spleen and liver of mice engrafted with AML cells that expressed higher CXCR4 at their surface or exhibited higher CXCL12 chemotaxis, suggesting that CXCR4 expression level and migratory response to CXCL12 may predict CXCR4 inhibitor efficacy.
CXCR4 inhibitors induced rapid mobilization of AML cells in NOG mice. We studied whether disruption of the CXCR4/CXCL12 axis would disturb the homing of leukemic cells. AML cells were treated or not in vitro with CXCR4 inhibitors, labeled by CSFE and i.v. injected into secondary hosts. No significant difference was observed in the 


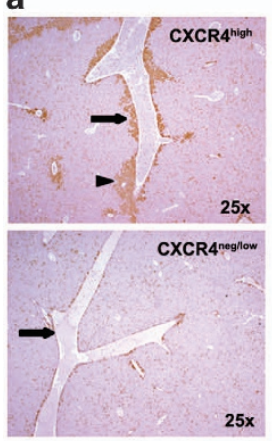

b

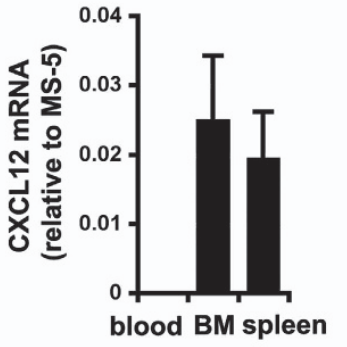

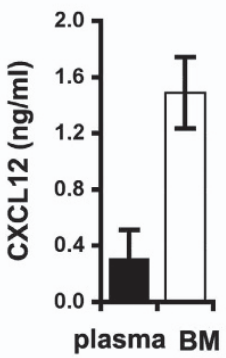

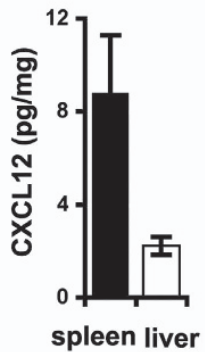

d

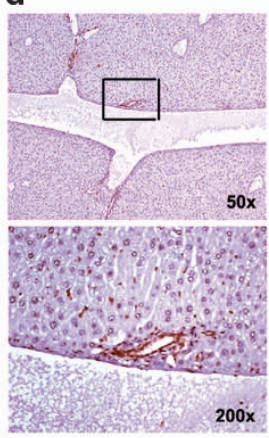

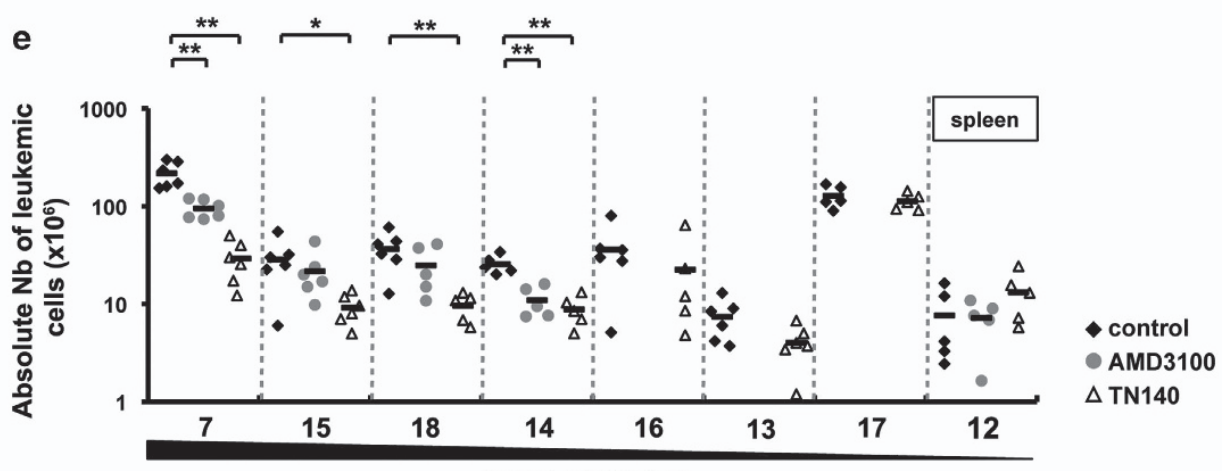

Level of CXCR4
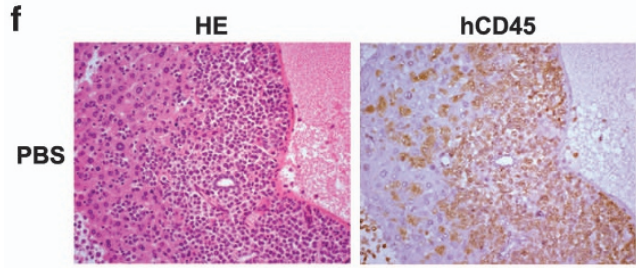

g
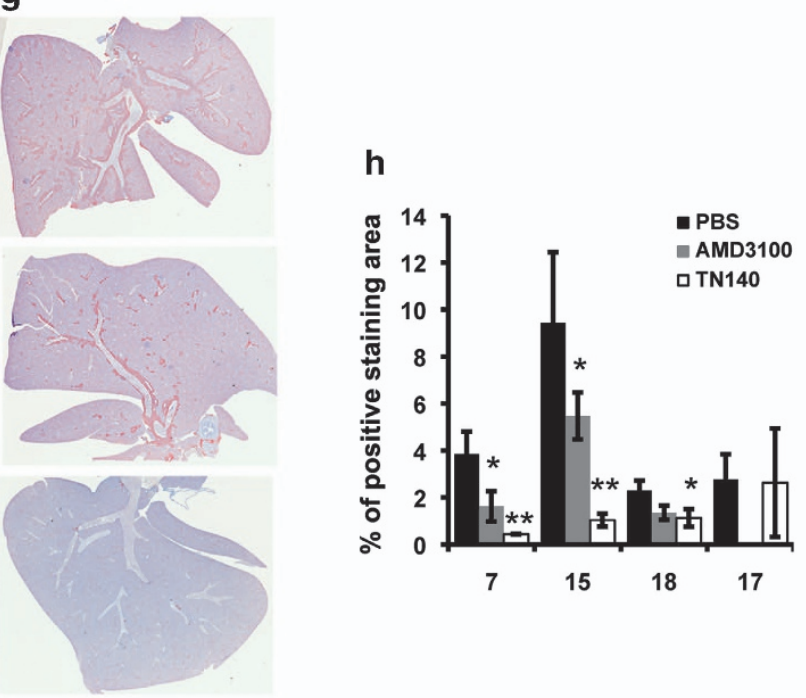

TN
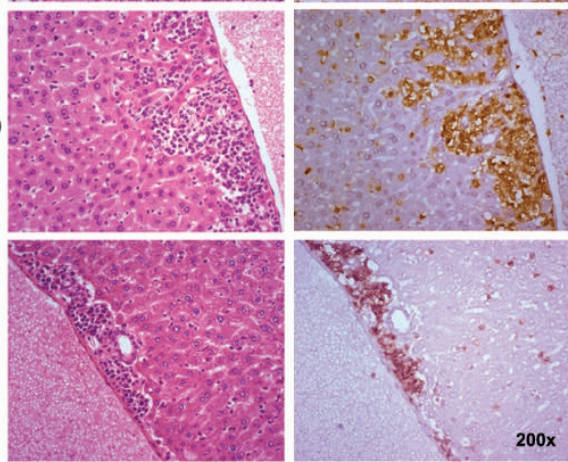

Figure 4 Localization of engrafted human leukemic cells according to CXCR4 expression level and CXCL12 production in organs microenvironment and CXCR4 inhibitors induce regression of CXCR4-expressing AMLs in the mouse tissues. (a) Localization of human leukemic cells in the mouse liver. Livers sections (16 weeks post transplant) were immunolabeled with an anti-CD45 mAb. Three CXCR4 $4^{\text {high }}$ (\#7, \#15 and \#18) and four CXCR4 ${ }^{\text {neg/low }}$ (\#12, \#13, \#16 and \#17) specimens were studied (four mice for each specimens) and gave comparable results. The figure illustrates data obtained with patient 15 (CXCR4 ${ }^{\text {high }}$ ) and patient 17 (CXCR4 ${ }^{\text {neg/low }}$ ). Solid arrow indicates big venous and thin arrow indicates a bile duct. (b) RT-PCR analysis for mRNA expression of CXCL12 in mononuclear cells isolated from peripheral blood, BM and spleen of NOG mice $(n=4)$. Amounts of CXCL12 mRNA were calculated relative to mRNA level of that in stroma cell line MS-5. (c) CXCL12 concentration in plasma, BM, spleen and liver supernatants prepared from normal NOG mice. Note that CXCL12 concentrations in spleen and liver are presented in pg per mg of tissue. Results are mean \pm S.D. ( $n=4$ mice, each determination in duplicated). (d) Localization of CXCL12 expression in liver from normal NOG mice. Immunolabeling with rabbit polyclonal anti-CXCL12 antibody visualized by peroxidase diaminobenzidine (brown color). (e) As described in Figure 3, leukemic mice were treated with PBS (control, black diamond), AMD3100 (gray circle) or TN140 (white triangle) for 7 days, spleen cells were counted and the percentage of human $\operatorname{CD} 45^{+} \operatorname{CD} 33^{+}$cells was determined by flow cytometry. Each point represents an individual mouse. Horizontal black bars indicate the average level of human cell numbers. Patient numbers are indicated below the graph with an arrow showing decreasing levels of CXCR4 expression by individual specimen. (f) Liver sections stained by hematoxylin eosin (left lane) and immunohistochemistry with anti-human CD45 antibodies (right lane) showing human cells in brown from PBS- (up lane), AMD3100- (middle lane) and TN140-treated (bottom lane) mice engrafted with cells from patient 15 ( $\times 200$ ). (g) Representative scanning images of whole sections of stained livers. (h) The percentage of positively stained area was calculated after scanning the whole liver sections. PBS (black bars), AMD3100 (gray bar) and TN140 (white bar). Data are mean \pm S.D. ( $n=4$ mice). ${ }^{\star} P<0.05,{ }^{\star \star} P<0.01$ assessed by test of Mann-Whitney 
distribution of human cells in the blood, BM and spleen (Figure 5a) despite efficient inhibitory effects of AMD3100 or TN140 on the binding of anti-CXCR4 antibody 12G5 to carboxyfluorescein diacetate $\mathrm{N}$-succinimidyl ester (CFSE) ${ }^{+}$ cells recovered from each organ (Figure $5 \mathrm{~b}$ ). In addition, no difference in the leukemic reconstitution was observed among recipients who received PBS- or inhibitor-treated cells (Figure 5c), suggesting that CXCR4 inhibitors did not alter homing capacity of LICs.

To further explore the mechanism of the leukemic regression induced by CXCR4 inhibitors, we evaluated the potential of CXCR4 inhibitors to mobilize AML cells. Leukemic mice were treated with the inhibitors for $24 \mathrm{~h}$, blood was collected and analyzed for $\mathrm{CD}_{4}{ }^{+}$cell numbers. In all but one case (\#13), the number of human cells was significantly increased in the blood of TN140-treated mice compared with controls. AMD3100 also resulted in a significant increase in human cell numbers except for one case (\#12) (Figure 6a). Leukemic progenitor cells circulating in blood were evaluated by methylcellulose colony assays. In all cases but one (\#12) treated with AMD3100, their number was significantly augmented (Figure 6b). Secondary transplantation of blood from treated and untreated animals showed that LICs were also mobilized to the circulation (Figure $6 \mathrm{c}$ ). These results and those showing a decrease in leukemic cell numbers in the BM of treated mice (Figure 3c) indicate that CXCR4 inhibition is associated with a mobilization of leukemic cells from the BM to blood.

To document the mobilizing effects of leukemic cells by CXCR4 inhibitors, experiments were performed after one acute subcutaneous injection of AMD3100 or TN140. Three hours after injection, spleens and livers of treated mice recover the red color of normal spleens and livers (Figure 7a). A significant increase in the number of leukemic cells measured in the blood of the treated was also observed, suggesting a rapid decrease in the white cell infiltration in these organs (Figure $7 \mathrm{~b}$ ). CXCR4/CXCL12 has been shown to trigger AKT and ERK signaling, which may account for the survival advantage conferred by CXCL12. ${ }^{34,35}$ We observed a marked decrease in ERK phosphorylation and to a less extent in AKT phosphorylation in leukemic cells recovered from the BM and spleen of AM3100- or TN140-treated mice. Increased levels of active cleaved caspase- 3 were also seen in the BM and spleen cells recovered from inhibitor-treated mice (Figure 7c). Altogether, these results indicate that CXCR4/ CXCL12 axis has a pivotal role in the retention of leukemic cells in BM as well as in extramedullary sites. Disruption of the interaction of leukemic cells with their microenvironment may promote their apoptosis and leukemia regression.

CXCR4 inhibitors disrupt adhesion of AML cells with stromal cells and induce their apoptosis in vitro. To understand the role of CXCR4 inhibitors, we performed in vitro experiments co-culturing CXCR4-expressing $\mathrm{AML}$ cells with stromal cells or CXCL12. The two drugs decreased the adhesion of AML cells to CXCL12-producing MS-5 stromal cells (Figures $8 a$ and $b$ ). In addition, in the absence of CXCL12 or stromal cells, a basal level of spontaneous apoptosis of AML cells was observed. This spontaneous apoptosis was not modified by AMD3100 or TN140 treatment
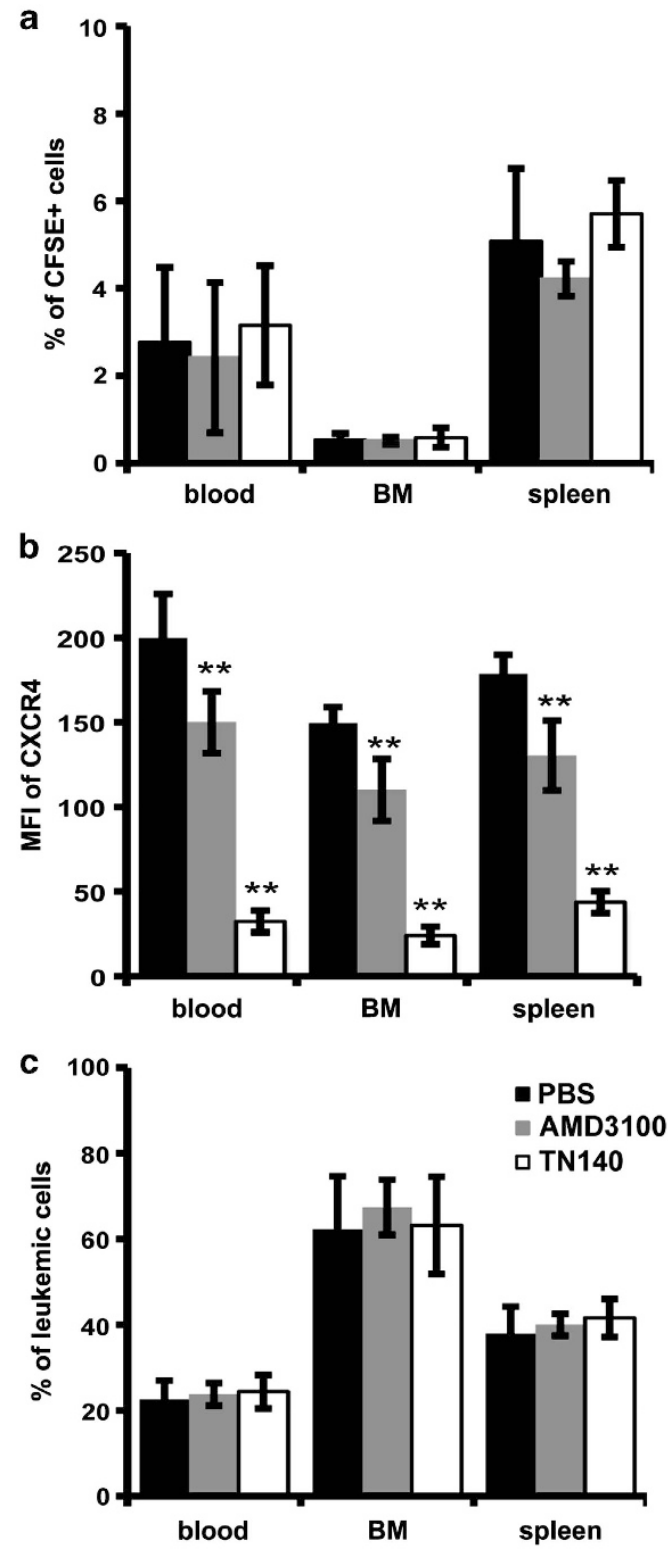

Figure 5 Homing and reconstitution capacity of the human AML cells in NOG mice are not modified by AMD3100 or TN140 treatment. Human leukemic cells were sorted (12 weeks post transplant) from the BM of an NOG mice engrafted with patient $7 \mathrm{AML}$ cells. Cells were labeled in vitro with CSFE, exposed to AMD3100 $(20 \mu \mathrm{M})$ (gray square), TN140 $(5 \mu \mathrm{M})$ (white square) or PBS (control) (black square), and i.v. injected $\left(20 \times 10^{6}\right.$ per NOG mice). Blood, BM and spleen of recipient mice were analyzed $3 \mathrm{~h}$ after injection. (a) Percentage of $\mathrm{CFSE}^{+}$ recovered cells. (b) Representative FACS analysis of CXCR4 expression on CFSE $^{+}$cells after homing. Data are mean \pm S.D. $(n=2,5$ mice per treatment) $\left({ }^{* *} P<0.01\right.$, Student's $t$-test). (c) NOG mice were i.v. injected with $1 \times 10^{5} \mathrm{AML}$ cells (patient 7) treated as above. Eight weeks later, the percentage of human $\mathrm{CD} 45^{+}$ cells circulating in blood was determined by flow cytometry. Data are mean \pm S.D. ( $n=2,5$ mice per treatment, $P>0.05$, Mann-Whitney test). Similar results were obtained with leukemic cells from patients 15 and 18 (data not shown)

(Figure 8c). Addition of CXCL12 in the medium or co-culture with MS-5 cells decreased the spontaneous apoptosis, an effect that was partially overcome by AMD3100 and, more importantly, by TN140 (Figure 8c). Thus, adhesion to stromal cells protects AML cells from spontaneous apoptosis and 

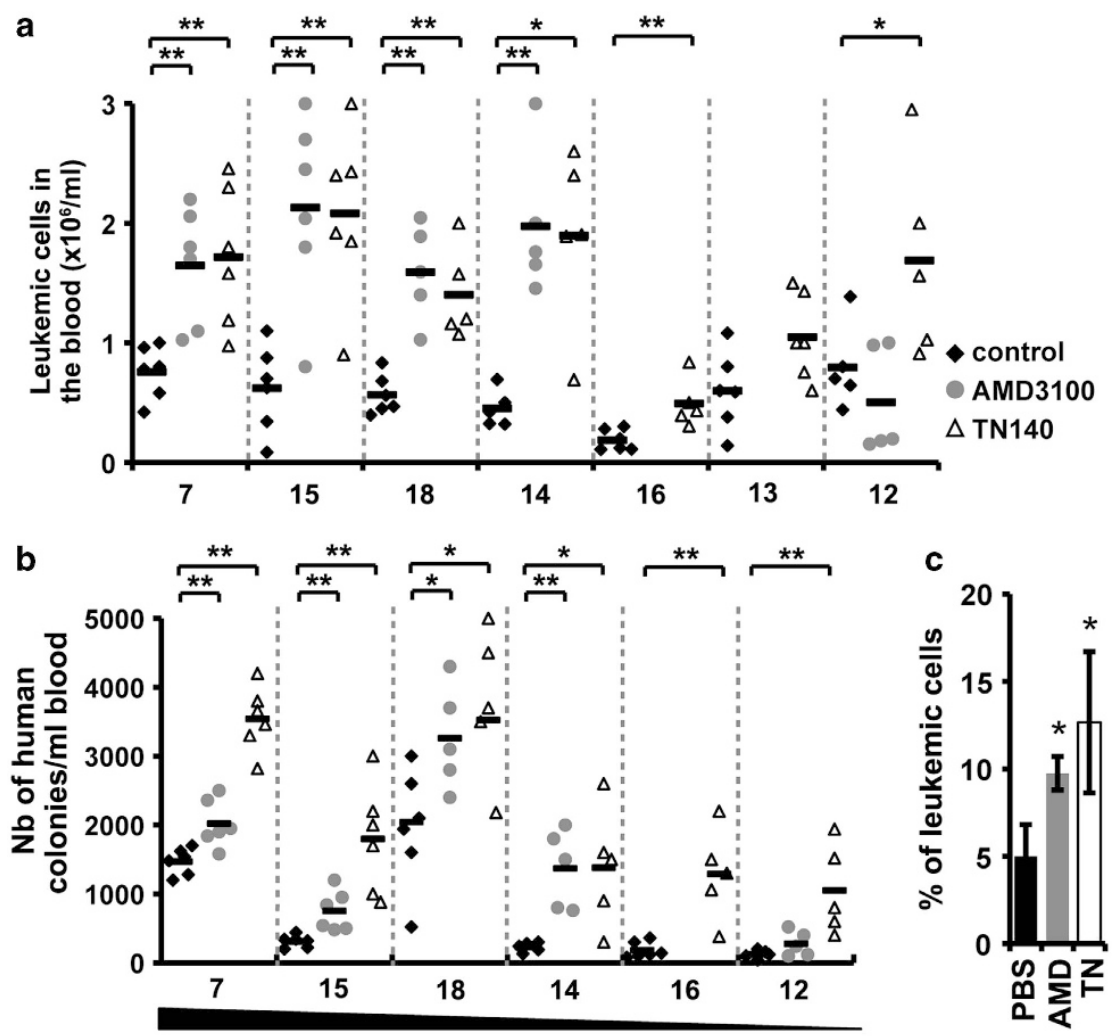

Level of CXCR4

Figure 6 CXCR4 inhibitors mobilize human bulk leukemic cells, progenitors and leukemic stem cells into peripheral blood. Twenty-four hours after PBS (black diamond), AMD3100 (gray circle) or TN140 (white triangle) treatment (as described in figure 4), numbers of human cells and progenitors circulating in blood were determined. Patient numbers are indicated below the graph with an arrow showing decreasing levels of CXCR4 expression by individual specimen. (a) Numbers of CD45 ${ }^{+} \mathrm{CD} 33^{+}$human cells in blood. (b) Numbers of human leukemic progenitors in blood determined in methycellulose culture medium. Colonies were counted after 14 days. Each symbol represents a single mouse and horizontal black bars indicate the average colony number (4-6 mice in each condition). Statistical differences are indicated as follows: ${ }^{*} P<0.05$, ${ }^{* *} P<0.01$ assessed by Mann-Whitney test. (c) Two hundred microliters of blood from PBS- (black bar), AMD3100- (gray bar) and TN140- (white bar) treated mice reconstituted with cells of patient 7 was recovered $24 \mathrm{~h}$ after treatment, red blood cells were lysed, nucleated cells were suspended in $200 \mu \mathrm{l} \mathrm{PBS}$ and injected into secondary mice. Eight weeks later, the percentage of human $\mathrm{CD} 45^{+}$cells in the blood of reconstituted mice was analyzed by cytometry. Results are mean \pm S.D. $(n=5$ mice). The same experiments were repeated three times. Statistical differences are indicated as follows: ${ }^{*} P<0.05$ assessed by Mann-Whitney test. Black arrow shows decreasing levels of CXCR4 expression by individual specimen

CXCL12 mimics this protective effect suggesting that the two tested inhibitors may target the interaction of CXCR4expressing leukemic cells with CXCL12 or stromal layers.

\section{Discussion}

The present study demonstrates in a mouse xenograft model that, when high levels of CXCR4 are expressed at the surface of $\mathrm{AML}$ cells, blocking the receptor function with small molecule inhibitors can promote leukemic cell death and reduce LICs. Conversely, these drugs have no efficacy when AML cells do not express CXCR4 or when they do not respond to CXCL12. Therefore, CXCR4 expression level on AML blast cells and their migratory response to $\mathrm{CXCL} 12$ are predictive of the response to the inhibitors, hence could be used as biomarkers to select patients that could potentially benefit from the drug. Since one of the tested CXCR4 antagonists has been approved for clinical therapy, such treatment could be rapidly evaluated in the treatment of CXCR4-positive AMLs.
Previous studies showed that AMD3100 or its analog AMD3465 enhanced the anti-leukemic effects of chemotherapy or that of the FLT3 inhibitors and resulted in markedly reduced leukemic burden and improved overall survival. ${ }^{29,30}$ These finding indicate that CXCL12/CXCR4 interactions contribute to the resistance of leukemic cells to signal transduction inhibitor- and chemotherapy-induced apoptosis. In our study, we used CXCR4 inhibitors as single agent and choose to use the xenotransplantation mouse model based on the NOG immunodeficient mice transplanted with primary patient cells.

The characteristics of the leukemia developed by each set of mice varied from patient to patient and xenotransplanted cells retained the fundamental biological characteristics of the original disease including the patient-specific pattern of CXCR4 expression and CXCL12-mediated chemotaxis. This indicates that these properties are modified neither by the xenotransplantation process nor by the murine microenvironment and likely depend on the particular genetic alterations present in the leukemic clone. Thus, transplantation of patient 


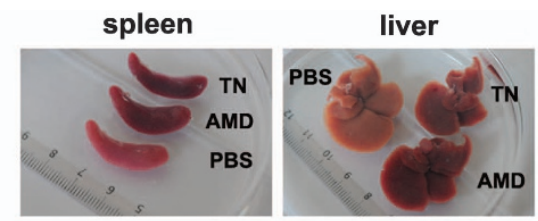

b

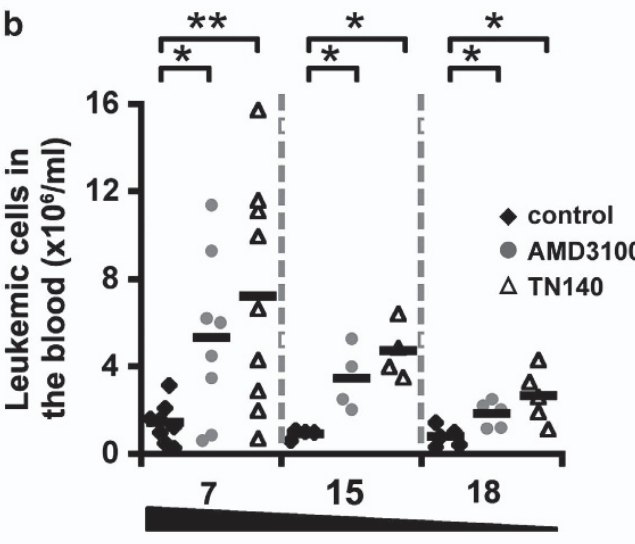

Level of CXCR4

C

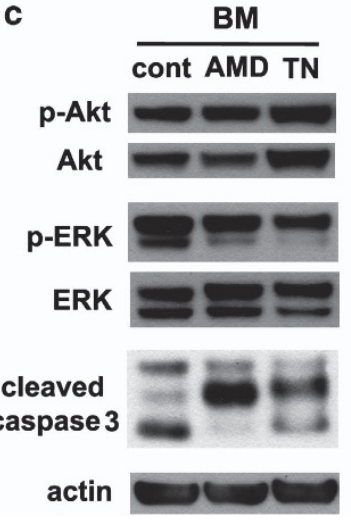

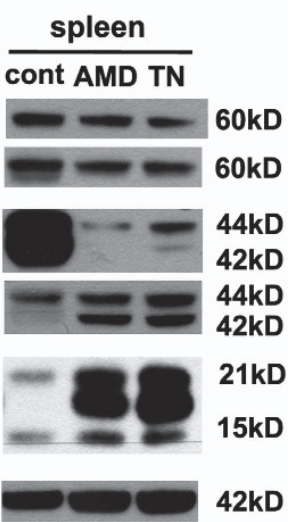

42kD

Figure 7 CXCR4 inhibitors induce rapid mobilization of human leukemic cells in blood and apoptosis in vivo. NOG mice engrafted with AML cells from patients indicated (12-16 weeks post transplant) were treated with an acute s.c. injection of AMD3100 (200 $\mu \mathrm{g} /$ mouse) or TN140 (200 $\mu \mathrm{g} /$ mouse) or PBS as control. Mice were examined $3 \mathrm{~h}$ later. (a) Comparison of the size and color of spleens and livers from PBS-, AMD3100- or TN140-treated mice. (b) Number of human CD45 ${ }^{+} \mathrm{CD} 33^{+}$ cells per milliliter of blood. Horizontal black bars indicate the average of 5-9 mice in each condition (PBS (black diamond), AMD3100 (gray circle) or TN140 (white triangle) was administered subcutaneously). Statistical differences are indicated as follows: ${ }^{*} P<0.05,{ }^{* *} P<0.01$ (Mann-Whitney test). (c) Whole cell extracts from human leukemic cells isolated from the BM and spleen of PBS- or AMD3100- and TN140-treated mice were immunoblotted with indicated antibodies and anti- $\beta$ actin antibody as loading control

cells in NOG mice results in the establishment of spectrum of murine models of human AML allowing addressing the roles of CXCR4 in the context of the disease heterogeneity.

AMD3100, which has been approved for clinical use, is currently used for HSPC mobilization in the transplantation setting and is a well-tolerated drug. ${ }^{36}$ TN140, a small peptide inhibitor that appears to be more efficient than AMD3100 in all our CXCR $4^{\text {high }}$ AML models, is not approved for clinical use so far. The two inhibitors were administered by continuous

subcutaneous infusion for 1 week in leukemic mice generated with primary cells from eight AML patients. Both and more strikingly TN140 induced an obvious reduction of BM leukemic cell number in four out of these eight cases. Importantly, three of the four responding cases belonged to the CXCR4 $4^{\text {high }}$ group and the remaining one (\#14) had the highest CXCR4 expression in the CXCR4 $4^{\text {neg/low }}$ group.

Importantly, this patient exhibits a CXCL12 migratory response similar to those of $\mathrm{CXCR} 4^{\text {high }}$ group in contrast to the four resistant cases that showed minimal response to CXCL12-mediated chemotaxis, indicating that CXCL12 chemotactic response is not strictly linked to CXCR4 expression. These results may be related to the multiple mechanisms that regulate CXCR4 membrane expression including cell surface trafficking and cleavage by proteolytic enzymes. ${ }^{37-39}$ Indeed, it was shown that AML cells express cytoplasmic CXCR4. ${ }^{40}$ These results imply that CXCR4 expression combined with efficient CXCL12 chemotactic responses may provides a powerful test to define responders to CXCR4 antagonist therapy. In addition, the four resistant cases showed minimal response to CXCL12-mediated chemotaxis, suggesting that the effect of AMD3100 and TN140 on the responding leukemia may be mediated by a direct inhibition of the CXCR4 receptor in vivo. A similar reduction in leukemia burden was observed with a neutralizing CXCR4 antibody in a xenograft model using primary human leukemic cells. ${ }^{40}$ However, in this study, no predictor of the drug activity has been identified.

High CXCR4 expression has been associated with the development of a more aggressive phenotype with an increased extramedullary organ infiltration in patients with acute lymphoid leukemia. ${ }^{41}$ When the distribution of engrafted AML cells in the NOG mice was analyzed in our series, we observed that leukemic cells from CXCR4 $4^{\text {high }}$ patients displayed specific localization in the mouse liver, which corresponds to the site of CXCL12 production, whereas the distribution of CXCR $4^{\text {neg/low }}$ cells in the liver was diffuse. CXCR4 antagonists induced a sharp decrease in CXCR4 $4^{\text {high }}$ leukemic cells in the BM, in the spleen and in the liver.

The mechanism of action of the two tested CXCR4 antagonists in AML is only partly understood. First, we showed that chronic or acute administration of these drugs results in a rapid mobilization of bulk leukemic cells and progenitors into the blood. To evaluate if the CXCR4 inhibitors targeted the LICs, we used a surrogate assay the capacity of a given sample to be xenografted. We preferred to measure the biological properties of LIC than to determine LIC-linked surface markers because previous studies have shown that there is considerable intersubject heterogeneity in LICaffiliated cell surface markers and an inability to apply them universally. ${ }^{42}$ Results showed that LICs were also mobilized in the blood, which is consistent with the role of CXCR4 in the retention of normal HSPC in the BM and the mobilizing effect of AMD3100 and TN140.

In a recent study, in AML patients, it was also shown that AMD3100 administered with chemotherapy induced a 2-fold mobilization in leukemic blasts. Thus, these drugs may disrupt the interaction of leukemic cells with their supportive niches. This is further demonstrated by in vitro experiments, in which CXCR4 antagonists decreased adhesion of leukemic cells to stromal cells, which promotes their death by apoptosis. 
a

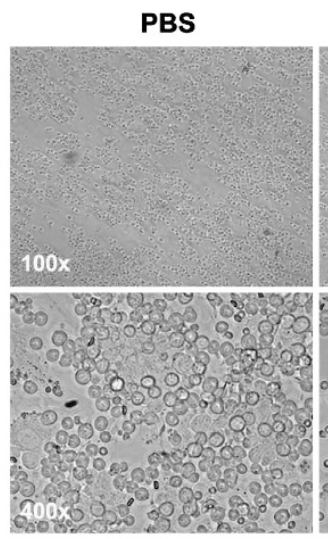

AMD3100

TN140

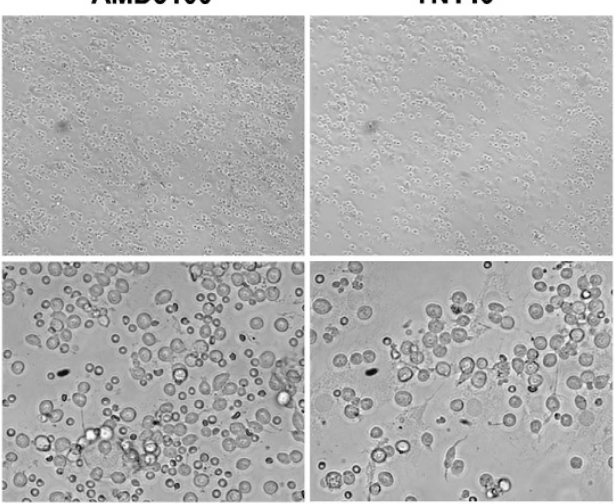

b
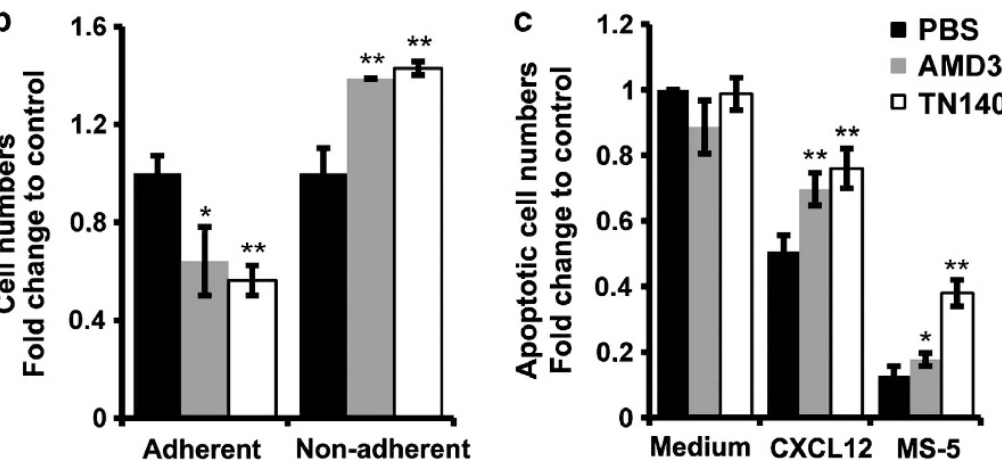

Figure 8 CXCR4 inhibitors disrupt CXCL2/CXCR4 interactions and induce apoptosis of AML cells in vitro. (a) Leukemic cells (\#18) pre-exposed to AMD3100 (20 $\mu$ M) or TN140 $(5 \mu \mathrm{M})$ were co-cultured with MS-5 stromal cells for $24 \mathrm{~h}$. Phase contrast microscopy showing reduced adhesion of inhibitor-treated leukemic cells $(\times 100, \times 400)$. (b) Non-adherent and adherent cells were collected and counted by flow cytometry. Histograms are mean \pm S.D. ( $n=3$ experiments in duplicate) (PBS (black bar), AMD3100 (gray bar) or TN140 (white bar)). (c) Leukemic cells (\#18) pre-exposed to medium alone, AMD3100 (20 $\mu \mathrm{M})$ or TN140 $(5 \mu \mathrm{M})$ at $37^{\circ} \mathrm{C}$ for 30 min and then incubated in medium alone (control) or medium supplemented with $100 \mathrm{ng} / \mathrm{ml}$ of CXCL12 or co-cultured with stromal cells MS-5 for $24 \mathrm{~h}$. Suspended cells were collected and apoptotic cells were detected by annexin V and propidium iodide labeling (PBS (black bar), AMD3100 (gray bar) or TN140 (white bar)). Results were normalized to PBS pre-treated cells cultured in medium alone. Data are mean \pm S.D. $\left(n=2\right.$ in triplicate). Statistical differences from the value of the control are indicated as follows: ${ }^{*} P<0.05 ;{ }^{* \star} P<0.01$ (Student's $t$-test). Similar results were obtained for patients 7 and 15 (data not shown)

Leukemic cells recovered in the BM and spleen after AM3100 or TN140 treatment demonstrated a marked decrease in ERK phosphorylation, suggesting that disruption of the interaction between stromal and leukemic cells induces a decrease in survival and proliferation signals.

Most importantly, CXCR4 antagonists prolonged the survival of treated mice and TN140 markedly decreased the capacities of BM leukemic cells to give leukemia after secondary transplantation underscoring that CXCR4 antagonists target LICs. These inhibitors could therefore be tested either in combination with initial chemotherapy or to eradicate residual disease after remission obtained with conventional treatment to decrease the risk of relapse. Of course, it will be important to understand its possible toxicity of long-term administration in advance since it is known that chronic administration of AMD3100 maybe toxic in HIV patients.

Of note, the mobilization effect of CXCR4 antagonists was not limited to $\mathrm{CXCR} 4^{\text {high }}$ cases, suggesting that blockage of CXCR4 is not the unique reason for AML cell mobilization. Alteration of hematopoietic microenvironment by CXCR4 inhibitors has been reported previously and may account for AML mobilization. ${ }^{43}$

In our hands, the TN140 inhibitor appears to be more efficient than AM3100. This may be related to relative longer half-life of TN140 or to its higher affinity to CXCR4. However, both AMD3100 and TN140 induced efficient mobilization of AML cells to the circulation, suggesting that both drugs are capable of 'priming' AML cells to enhance sensitivity to chemotherapy in both CXCR $4^{\text {high }}$ and CXCR $4^{\text {neg/low }}$ patients.

In summary, our study identifies two groups of AMLs according to their positive or negative response to CXCR4 inhibitors, and demonstrates that CXCR4 blocking agents effectively antagonize CXCL12-promoted leukemic development in selected patients characterized by high CXCR4 expression and CXCL12 migratory response. Since overexpression of CXCR4 and engraftment in immunodeficient mice are two poor prognostic factors in AMLs, the ability of CXCR4 antagonists to improve the clinical results in this disease now deserves to be tested. As this study suggests an effect on LICs, this anti-CXCR4 therapy might be interesting not only to modulate the effect of chemotherapy, but also to target residual LICs after remission to avoid relapse

\section{Materials and Methods}

Patient samples. AML samples from BM $(n=3)$ or peripheral blood $(n=44)$ were collected from patients at diagnosis after informed consent and following protocols approved by local Research Ethics Committees from Gustave Roussy Institute (Villejuif, France) and Saint Antoine Hospital (Paris, France). 
Mice. NOG mice were bred and maintained under specific pathogen-free conditions at the animal facility of Gustave Roussy Institute. Animal experiments were performed in accordance with guidelines established by the Institutional Animal Committee.

CXCR4 expression analysis. Mononuclear cells were triple-stained with an APC-conjugated anti-CD34 mAb, an FITC-conjugated anti-human CD45 mAb and a PE-conjugated anti-CXCR4 mAb (12G5). Appropriate Ig isotypes were used as controls. All antibodies were from BD Pharmingen (Le Pont De Claix, France). Quantitative analyses of fluorescence intensity were performed on gated $\mathrm{CD} 45^{\text {low }}$ and/or $\mathrm{CD}_{3} 4^{+}$cells and the mean fluorescence intensity (MFI) was calculated. MFIRs were calculated by dividing the MFI for CXCR4 by the MFI of the respective non-specific isotype control. To analyze CXCR4 expression level on human cell populations proliferating in the NOG mouse, a PE/Cy7-conjugated rat anti-mouse CD45 mAb was used in addition to the three mAbs mentioned above. MFI of CXCR4 was calculated on the gated human $\mathrm{CD}_{4} 5^{+}$population.

Chemotaxis assay. Migration assays were performed with $5 \mu \mathrm{m}$-pore filters chambers (Transwell, ThinCert 24-well Translucent RoTrac; Greiner Bio-one, Courtaboeuf, France) as previously described. ${ }^{44}$ To evaluate the migratory capacity of the human leukemic cells isolated from the BM of engrafted mice, a rat anti-mouse CD45 mAb was used to distinguish murine and human cells. All assays were done in triplicate.

Xenogeneic transplantation and assessment of engraftment. Mononuclear cells from AML patients were depleted of $\mathrm{CD}^{+}$cells by RosetteSep human $\mathrm{CD}^{+}$depletion cocktail (StemCell Technologies, Grenoble, France) and $5 \times 10^{6}$ cells were i.v. injected to mice $24 \mathrm{~h}$ later after irradiated at $2.5 \mathrm{~Gy}$ from a ${ }^{137}$ cesium source. Mononuclear cells collected from blood, BM and spleen of euthanatized mice were stained with rat anti-mouse CD45 (Beckman Coulter, Villepinte, France), mouse anti-human CD45, CD19 and CD33 mAb (all from BD Pharmingen). The presence of a single $\mathrm{CD} 45^{+} \mathrm{CD} 33^{+} \mathrm{CD} 19^{-}$population in the human $\mathrm{CD} 45^{+}$population was considered as AML engraftment. ${ }^{33}$ The number of human leukemic cells was calculated by the equation: total cell number $\times \%$ of human $\mathrm{CD}_{4}{ }^{+} \mathrm{CD}^{+} 3^{+}$cells.

Treatment with CXCR4 inhibitors. AMD3100 (Sigma-Aldrich, Saint Quentin Fallavier, France) $(20 \mathrm{mg} / \mathrm{kg} / \mathrm{day})$ and $\mathrm{TN} 140^{33}(24 \mathrm{mg} / \mathrm{kg} / \mathrm{day})$ were administered s.c. by Alzet osmotic pump (Durect Corporation, Cupertino, CA, USA). Control animals received pumps containing PBS. After 7 days, blood, BM and spleens were analyzed for total cell numbers and the presence of leukemic cells by flow cytometry. For short assays, AMD3100 (200 $\mu \mathrm{g} /$ mouse) or TN140 $(100 \mu \mathrm{g} /$ mouse) was given in a single s.c. injection and mice were killed $3 \mathrm{~h}$ later.

Secondary transplantation. For secondary transplantation performed with BM cells, one femur and two tibias were flushed in $1 \mathrm{ml}$ PBS. In all, $100 \mu \mathrm{l}$ was i.v. injected into irradiated mice. For secondary transplantation with blood, $200 \mu \mathrm{l}$ of blood was recovered $24 \mathrm{~h}$ after treatment and nucleated cells were injected into irradiated recipients. Human cells engraftment was assessed 8 weeks later.

Assessment of human hematopoietic clonogenic progenitors. Fifty microliters of blood from mice was lysed and plated in human complete methylcellulose medium and scored at day 14 as previously described. ${ }^{45}$

Histopathology and immunohistochemistry. Deparaffinized liver sections processed for heat-induced antigen retrieval were incubated with a mouse anti-human CD45 mAb (Dako, Trappes, France) or a rabbit polyclonal antiCXCL12 antibody (eBioscience, Paris, France). Staining was visualized by Histomouse Kit (Zymed, South San Francisco, CA, USA) or Rabbit PowerVision kit (ImmunoVision Technologies, Hillsborough, CA, USA). The sections were counterstained with hematoxylin and examined by a Zeiss Axiophot microscope (Carl Zeiss, Le Pecq, France). Whole sections of liver were scanned (Nikon, Val de Marne, France) and adobe photoshop software was used to calculate the total tissue area and the area of positive immunostaining.

CXCL12 measurements. Plasma was prepared from the citrated blood. One femur and two tibias were flushed in $1 \mathrm{ml}$ of PBS. Spleen and liver were crushed in $2 \mathrm{ml} \mathrm{PBS}$, respectively. CXCL12 levels in the supernatant and plasma were evaluated by an ELISA system (R\&D Systems, Lille, France).
Homing assay. Leukemic cells $\left(20 \times 10^{6}\right)$ from $\mathrm{BM}$ of reconstituted mice were stained with $1 \mu \mathrm{M} 5(6)$ carboxyfluorescein diacetate $\mathrm{N}$-succinimidyl ester (CFSE; Sigma-Aldrich). Just prior intravenous injection into irradiated mice, cells were incubated for $30 \mathrm{~min}$ at $37^{\circ} \mathrm{C}$ either with PBS or with AMD3100 $(20 \mu \mathrm{M})$ or TN140 $(5 \mu \mathrm{M})$. Three hours after injection, cells were recovered from the blood, $\mathrm{BM}$ and spleen and analyzed by FACSort cytometry to determine the percentage of CFSE bright cells. To verify the homing capacity of LICs, a low dose $\left(0.1 \times 10^{6}\right)$ of cells treated as above were inoculated into irradiated mice. The presence of human cells in the mouse BM was evaluated 8 weeks later.

Adhesion and apoptosis assay. Cells pre-incubated in the medium alone or with AMD3100 $20 \mu \mathrm{M}$ or TN140 $5 \mu \mathrm{M}$ at $37^{\circ} \mathrm{C}$ for 30 min were seeded on the top of MS-5 stromal cells supplemented with the inhibitors at the same concentration. Non-adherent and adherent cells were separately collected $24 \mathrm{~h}$ later and labeled with anti-human CD45 mAb followed by counting on flow cytometry. Non-adherent and adherent cell numbers were calculated on the gated human $\mathrm{CD}^{+} 5^{+}$population.

For the cell viability assays, pre-incubation of AML cells without or with inhibitors was done as above. Without washing, cells were seeded in the medium alone or medium supplemented with CXCL12 $100 \mathrm{ng} / \mathrm{ml}$ or on the top of MS- 5 stromal cells. Twenty-four hours later, non-adherent cells were labeled with anti-human CD45 $\mathrm{mAb}$ and processed to FITC conjugated-annexin V labeling (BD Pharmingen). The percentage of apoptotic cells was calculated on the gated human CD $45^{+}$ population by flow cytometry.

Immunoblotting. Cells were lysed in ice-cold lysis buffer (NP-40 1\%, HEPES $20 \mathrm{mM}, \mathrm{KCl} 10 \mathrm{mM}$, EDTA $1 \mathrm{mM}$, Glycerol $10 \%$, protease inhibitors cocktail Complete (Roche, Meylan, France)). Protein was separated on polyacrylamide gel electrophoresis (Invitrogen, Saint Aubin, France) and transferred onto PVDF membranes. The following primary antibodies were used: anti-caspase 3 , antiphospho ERK, anti-ERK, anti-phospho Akt, anti-Akt (Cell Signaling, Danvers, MA, USA). Proteins were visualized with horseradish peroxidase-conjugated secondary antibody and chemoluminescent substrate on CL-Xposure films (Pierce, Thermo Scientific, Illkirch, France). Anti-actin (AbCys, Paris, France) antibody was used to control equal loading.

Statistics. Data are reported as the mean \pm S.D. Differences in the distribution of continuous variables between categories were analyzed by Mann-Whitney test and Student's $t$-test. The BiostaTGV (http://marne.u707.jussieu.fr/biostatgv) statistical package was used for these calculations. For survival analysis, the Kaplan-Meier method of R software was used (http://www.r-project.org/). The logrank test was used to check for equality of the survival distributions. In all evaluation, differences were considered as significant if the $P$-value was $<0.05$.

\section{Conflict of Interest}

The authors declare no conflict of interest.

Acknowledgements. This work was supported by grants from INSERM, the Agence Nationale de la Recherche (ANR-BiotecS), the Fondation Institut Gustave Roussy, Fondation de France, Université Paris 11, Association Laurette Fugain and Association Cent pour Cent la vie and Cancéropole, Ile de France. YZ was supported by CreMEC consortium and by a postdoctoral fellowship from ANR and the Institut du Cancer (INCa). We thank all patients for providing samples for our studies. Benoît Petit, Aurélie Gasnier and Karine Ser-Le Roux in Service Commun d'Expérimentation Animale provided excellent animal colony care. We are grateful to Dr. Françoise Wendling and Dr. Dominique Bonnet for helpful suggestions and critical reading the manuscript.

1. Aiuti A, Webb IJ, Bleul C, Springer T, Gutierrez-Ramos JC. The chemokine SDF-1 is a chemoattractant for human CD34 + hematopoietic progenitor cells and provides a new mechanism to explain the mobilization of CD34 + progenitors to peripheral blood. J Exp Med 1997; 185: 111-120.

2. Bleul CC, Farzan M, Choe H, Parolin C, Clark-Lewis I, Sodroski J et al. The lymphocyte chemoattractant SDF-1 is a ligand for LESTR/fusin and blocks HIV-1 entry. Nature 1996; 382: 829-833. 
3. Oberlin E, Amara A, Bachelerie F, Bessia C, Virelizier JL, Arenzana-Seisdedos F et al. The CXC chemokine SDF-1 is the ligand for LESTR/fusin and prevents infection by T-cell-lineadapted HIV-1. Nature 1996; 382: 833-835.

4. Ma $Q$, Jones $D$, Borghesani PR, Segal RA, Nagasawa T, Kishimoto $T$ et al. Impaired B-lymphopoiesis, myelopoiesis, and derailed cerebellar neuron migration in CXCR4- and SDF-1-deficient mice. Proc Natl Acad Sci USA 1998; 95: 9448-9453.

5. Zou YR, Kottmann AH, Kuroda M, Taniuchi I, Littman DR. Function of the chemokine receptor CXCR4 in haematopoiesis and in cerebellar development. Nature 1998; 393: 595-599.

6. Nagasawa T, Tachibana K, Kishimoto T. A novel CXC chemokine PBSF/SDF-1 and its receptor CXCR4: their functions in development, hematopoiesis and HIV infection. Semin Immunol 1998; 10: 179-185.

7. Nie Y, Han YC, Zou YR. CXCR4 is required for the quiescence of primitive hematopoietic cells. J Exp Med 2008; 205: 777-783.

8. Peled A, Kollet O, Ponomaryov T, Petit I, Franitza S, Grabovsky V et al. The chemokine SDF-1 activates the integrins LFA-1, VLA-4, and VLA-5 on immature human CD34 $(+)$ cells: role in transendothelial/stromal migration and engraftment of NOD/SCID mice. Blood 2000; 95: 3289-3296.

9. Avigdor A, Goichberg P, Shivtiel S, Dar A, Peled A, Samira S et al. CD44 and hyaluronic acid cooperate with SDF-1 in the trafficking of human CD34 + stem/progenitor cells to bone marrow. Blood 2004; 103: 2981-2989.

10. Sugiyama T, Kohara H, Noda M, Nagasawa T. Maintenance of the hematopoietic stem cell pool by CXCL12-CXCR4 chemokine signaling in bone marrow stromal cell niches. Immunity 2006; 25: 977-988.

11. Foudi A, Jarrier $P$, Zhang $Y$, Wittner M, Geay JF, Lecluse $Y$ et al. Reduced retention of radioprotective hematopoietic cells within the bone marrow microenvironment in CXCR4-/ chimeric mice. Blood 2006; 107: 2243-2251.

12. Broxmeyer HE, Kohli L, Kim CH, Lee Y, Mantel C, Cooper S et al. Stromal cell-derived factor-1/CXCL12 directly enhances survival/antiapoptosis of myeloid progenitor cells through CXCR4 and G(alpha)i proteins and enhances engraftment of competitive, repopulating stem cells. J Leukoc Biol 2003; 73: 630-638.

13. Lataillade JJ, Clay D, Dupuy C, Rigal S, Jasmin C, Bourin P et al. Chemokine SDF-1 enhances circulating $\operatorname{CD} 34(+)$ cell proliferation in synergy with cytokines: possible role in progenitor survival. Blood 2000; 95: 756-768.

14. Devine SM, Vij R, Rettig M, Todt L, McGlauchlen K, Fisher N et al. Rapid mobilization of functional donor hematopoietic cells without G-CSF using AMD3100, an antagonist of the CXCR4/SDF-1 interaction. Blood 2008; 112: 990-998.

15. Liles WC, Broxmeyer HE, Rodger E, Wood B, Hubel K, Cooper S et al. Mobilization of hematopoietic progenitor cells in healthy volunteers by AMD3100, a CXCR4 antagonist. Blood 2003; 102: 2728-2730.

16. Cashen AF, Nervi B, DiPersio J. AMD3100: CXCR4 antagonist and rapid stem cellmobilizing agent. Future Oncol 2007; 3: 19-27.

17. Abraham M, Biyder K, Begin M, Wald H, Weiss ID, Galun E et al. Enhanced unique pattern of hematopoietic cell mobilization induced by the CXCR4 antagonist 4F-benzoyl-TN14003. Stem Cells 2007; 25: 2158-2166.

18. Sutherland HJ, Blair A, Zapf RW. Characterization of a hierarchy in human acute myeloid leukemia progenitor cells. Blood 1996; 87: 4754-4761.

19. Huntly BJ, Gilliland DG. Leukaemia stem cells and the evolution of cancer-stem-cell research. Nat Rev Cancer 2005; 5: 311-321.

20. Lapidot T, Sirard C, Vormoor J, Murdoch B, Hoang T, Caceres-Cortes $\mathrm{J}$ et al. A cell initiating human acute myeloid leukaemia after transplantation into SCID mice. Nature 1994; 367: 645-648.

21. Bonnet $D$, Dick JE. Human acute myeloid leukemia is organized as a hierarchy that originates from a primitive hematopoietic cell. Nat Med 1997; 3: 730-737.

22. Wang JC, Lapidot T, Cashman JD, Doedens M, Addy L, Sutherland DR et al. High level engraftment of NOD/SCID mice by primitive normal and leukemic hematopoietic cells from patients with chronic myeloid leukemia in chronic phase. Blood 1998; 91: 2406-2414.

23. Lane SW, Scadden DT, Gilliland DG. The leukemic stem cell niche: current concepts and therapeutic opportunities. Blood 2009; 114: 1150-1157.

24. Huntly BJ, Shigematsu H, Deguchi K, Lee BH, Mizuno S, Duclos N et al. MOZ-TIF2, but not BCR-ABL, confers properties of leukemic stem cells to committed murine hematopoietic progenitors. Cancer Cell 2004; 6: 587-596.

25. Kato I, Niwa A, Heike T, Fujino H, Saito MK, Umeda K et al. Identification of Hepatic Niche Harboring Human Acute Lymphoblastic Leukemic Cells via the SDF-1/CXCR4 Axis. PLoS One 2011; 6: e27042.

26. Tavor S, Petit I, Porozov S, Goichberg P, Avigdor A, Sagiv S et al. Motility, proliferation, and egress to the circulation of human AML cells are elastase dependent in NOD/SCID chimeric mice. Blood 2005; 106: 2120-2127.

27. Spoo AC, Lubbert M, Wierda WG, Burger JA. CXCR4 is a prognostic marker in acute myelogenous leukemia. Blood 2007; 109: 786-791.

28. Rombouts EJ, Pavic B, Lowenberg B, Ploemacher RE. Relation between CXCR-4 expression, Flt3 mutations, and unfavorable prognosis of adult acute myeloid leukemia. Blood 2004; 104: 550-557

29. Zeng Z, Shi YX, Samudio IJ, Wang RY, Ling X, Frolova $O$ et al. Targeting the leukemia microenvironment by CXCR4 inhibition overcomes resistance to kinase inhibitors and chemotherapy in AML. Blood 2009; 113: 6215-6224.

30. Nervi B, Ramirez P, Rettig MP, Uy GL, Holt MS, Ritchey JK et al. Chemosensitization of acute myeloid leukemia (AML) following mobilization by the CXCR4 antagonist AMD3100. Blood 2009; 113: 6206-6214.

31. Uy GL, Rettig MP, Motabi IH, McFarland K, Trinkaus KM, Hladnik LM et al. A phase 1/2 study of chemosensitization with the CXCR4 antagonist plerixafor in relapsed or refractory acute myeloid leukemia. Blood 2012; 119: 3917-3924.

32. Hendrix CW, Flexner C, MacFarland RT, Giandomenico C, Fuchs EJ, Redpath E et al. Pharmacokinetics and safety of AMD-3100, a novel antagonist of the CXCR-4 chemokine receptor, in human volunteers. Antimicrob Agents Chemother 2000; 44: 1667-1673.

33. Fujii N, Nakashima H, Tamamura $\mathrm{H}$. The therapeutic potential of CXCR4 antagonists in the treatment of HIV. Expert Opin Investig Drugs 2003; 12: 185-195.

34. Lataillade JJ, Clay D, Bourin P, Herodin F, Dupuy C, Jasmin C et al. Stromal cell-derived factor 1 regulates primitive hematopoiesis by suppressing apoptosis and by promoting $\mathrm{G}(0) / \mathrm{G}(1)$ transition in $\mathrm{CD} 34(+)$ cells: evidence for an autocrine/paracrine mechanism. Blood 2002; 99: 1117-1129.

35. Lee Y, Gotoh A, Kwon HJ, You M, Kohli L, Mantel C et al. Enhancement of intracellular signaling associated with hematopoietic progenitor cell survival in response to SDF-1/CXCL12 in synergy with other cytokines. Blood 2002; 99: 4307-4317.

36. Pusic I, DiPersio JF. Update on clinical experience with AMD3100, an SDF-1/CXCL12CXCR4 inhibitor, in mobilization of hematopoietic stem and progenitor cells. Curr Opin Hematol 2008; 17: 319-326.

37. Zhang Y, Foudi A, Geay JF, Berthebaud M, Buet D, Jarrier P et al. Intracellular localization and constitutive endocytosis of CXCR4 in human CD34 + hematopoietic progenitor cells. Stem Cells 2004; 22: 1015-1029.

38. Levesque JP, Hendy J, Takamatsu Y, Simmons PJ, Bendall LJ. Disruption of the CXCR4/ CXCL12 chemotactic interaction during hematopoietic stem cell mobilization induced by GCSF or cyclophosphamide. J Clin Invest 2003; 111: 187-196.

39. Sadir R, Imberty A, Baleux F, Lortat-Jacob H. Heparan sulfate/heparin oligosaccharides protect stromal cell-derived factor-1 (SDF-1)/CXCL12 against proteolysis induced by CD26/dipeptidyl peptidase IV. J Biol Chem 2004; 279: 43854-43860.

40. Tavor S, Petit I, Porozov S, Avigdor A, Dar A, Leider-Trejo L et al. CXCR4 regulates migration and development of human acute myelogenous leukemia stem cells in transplanted NOD/SCID mice. Cancer Res 2004; 64: 2817-2824.

41. Crazzolara R, Kreczy A, Mann G, Heitger A, Eibl G, Fink FM et al. High expression of the chemokine receptor CXCR4 predicts extramedullary organ infiltration in childhood acute lymphoblastic leukaemia. Br J Haematol 2001; 115: 545-553.

42. Eppert KA, Takenaka K, Lechman ER, Waldron L, Nilsson B, van Galen PA et al. Stem cell gene expression programs influence clinical outcome in human leukemia. Nat Med 2011; 17: $1086-1093$.

43. Dar A, Schajnovitz A, Lapid K, Kalinkovich A, Itkin T, Ludin A et al. Rapid mobilization of hematopoietic progenitors by AMD3100 and catecholamines is mediated by CXCR4-dependent SDF-1 release from bone marrow stromal cells. Leukemia 2011; 25: 1286-1296.

44. Zhang $Y$, Wittner M, Bouamar H, Jarrier P, Vainchenker W, Louache F. Identification of CXCR4 as a new nitric oxide-regulated gene in human CD34 + cells. Stem Cells 2007; 25: 211-219.

45. Marandin A, Katz A, Oksenhendler E, Tulliez M, Picard F, Vainchenker W et al. Loss of primitive hematopoietic progenitors in patients with human immunodeficiency virus infection. Blood 1996; 88: 4568-4578.

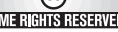

Cell Death and Disease is an open-access journal published by Nature Publishing Group. This work is licensed under the Creative Commons Attribution-NonCommercialShare Alike 3.0 Unported License. To view a copy of this license, visit http://creativecommons.org/licenses/by-nc-sa/3.0/

Supplementary Information accompanies the paper on Cell Death and Disease website (http://www.nature.com/cddis) 